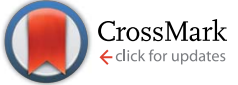

Cite this: Chem. Sci., 2015, 6, 6908

\title{
Amorphous cobalt silicate nanobelts@carbon composites as a stable anode material for lithium ion batteries $\uparrow$
}

\author{
Wei Cheng, ${ }^{a}$ Felix Rechberger, ${ }^{a}$ Gabriele Ilari, ${ }^{\text {ab }}$ Huan Ma, ${ }^{c}$ Wan-Ing Lin ${ }^{d}$ \\ and Markus Niederberger ${ }^{\star a}$
}

During the past decade, tremendous attention has been given to the development of new electrode materials with high capacity to meet the requirements of electrode materials with high energy density in lithium ion batteries. Very recently, cobalt silicate has been proposed as a new type of high capacity anode material for lithium ion batteries. However, the bulky cobalt silicate demonstrates limited electrochemical performance. Nanostructure engineering and carbon coating represent two promising strategies to improve the electrochemical performance of electrode materials. Herein, we developed a template method for the synthesis of amorphous cobalt silicate nanobelts which can be coated with carbon through the deposition and thermal decomposition of phenol formaldehyde resin. Tested as an anode material, the amorphous cobalt silicate nanobeltsacarbon composites exhibit a reversible high capacity of $745 \mathrm{~mA} \mathrm{~h} \mathrm{~g}^{-1}$ at a current density of $100 \mathrm{~mA} \mathrm{~g}^{-1}$, and a long life span of up to 1000 cycles with a stable capacity retention of $480 \mathrm{~mA} \mathrm{~h} \mathrm{~g}{ }^{-1}$ at a current density of $500 \mathrm{~mA} \mathrm{~g}^{-1}$. The outstanding electrochemical performance of the composites indicates their high potential as an anode material for lithium ion batteries. The results here are expected to stimulate further research into transition metal silicate nanostructures for lithium ion battery applications.

Received 13th July 2015

Accepted 25th August 2015

DOI: $10.1039 / \mathrm{c} 5 \mathrm{sc} 02525 \mathrm{~g}$

www.rsc.org/chemicalscience

\section{Introduction}

Lithium ion batteries are nowadays one of the most popular electrical energy storage technologies on the market, because of their relatively high energy density as well as good cycling stability. ${ }^{1-3}$ Regarding the anode in lithium ion batteries, intercalating graphite is the mostly used commercial material. However, graphite offers a low theoretical capacity of only $372 \mathrm{~mA} \mathrm{~h} \mathrm{~g}^{-1}$, and also a relatively poor rate performance. These limitations restrict the use of lithium ion batteries in large scale applications such as in electrical vehicles, electric grids and renewable power plants. ${ }^{3,4}$ Consequently, extensive research efforts have been dedicated to finding new anode materials with

${ }^{a}$ Laboratory for Multifunctional Materials, Department of Materials, ETH Zurich, Vladimir-Prelog-Weg 5, 8093 Zurich, Switzerland. E-mail: markus.niederberger@ mat.ethz.ch

${ }^{b}$ Electron Microscopy Center, Empa, Swiss Federal Laboratories for Materials Science and Technology, Überlandstrasse 129, 8600 Dübendorf, Switzerland

${ }^{c}$ Laboratory for Nanometallurgy, Department of Materials, ETH Zurich, 8093 Zurich, Switzerland

${ }^{d}$ Department of Chemistry and Applied Biosciences, ETH Zurich, 8093 Zurich, Switzerland

$\dagger$ Electronic supplementary information (ESI) available: Experimental details, AFM images, XRD patterns, SEM images, SEM-EDX element mapping, TEM images, Raman spectrum, TGA analysis, IR spectra, electrochemical characterization and $\mathrm{N}_{2}$ gas sorption measurements. See DOI: $10.1039 / \mathrm{c} 5 \mathrm{sc} 02525 \mathrm{~g}$ high capacity. ${ }^{5-9}$ Among all the emerging high capacity anode materials, Si-based inorganic materials, including $\mathrm{Si}$ and $\mathrm{SiO}_{2}$, have received most of the attention due to their extremely high theoretical capacities $\left(4200 \mathrm{~mA} \mathrm{~h} \mathrm{~g}^{-1}\right.$ for Si and $1965 \mathrm{~mA} \mathrm{~h} \mathrm{~g}^{-1}$ for $\mathrm{SiO}_{2}$ ) and the abundance of the element silicon in the Earth's crust. ${ }^{10,11}$ However, both compounds suffer from drastic capacity fading during cycling. This issue can be addressed by a careful engineering of the nanostructure and by depositing a conductive coating. ${ }^{10,11}$ In addition to $\mathrm{Si}$ and $\mathrm{SiO}_{2}$, metal silicates represent another type of potential electrode material. In contrast to lithium metal silicates $\left(\mathrm{Li}_{2} \mathrm{MSiO}_{4}, \mathrm{M}=\mathrm{Fe}, \mathrm{Co}, \mathrm{Mn}\right)$, which have been extensively investigated as cathodes, ${ }^{12}$ metal silicates such as $\mathrm{M}_{2} \mathrm{SiO}_{4}(\mathrm{M}=\mathrm{Co}, \mathrm{Fe}, \mathrm{Mn})$ have rarely been studied as electrode materials for lithium ion batteries. Only very recently, Mueller et al. reported that cobalt silicate can be used as an anode which undergoes a conversion reaction during lithiation and delithiation, providing a reversible specific capacity of about $600 \mathrm{~mA} \mathrm{~h} \mathrm{~g}{ }^{-1} \cdot{ }^{13}$ However, this bulky cobalt silicate exhibited limited capacity and poor cycling stability and rate performance due to the large particle size. Accordingly, there are still many possibilities to study metal silicates as anode materials and to improve their electrochemical performances by downscaling the particle size to the $\mathrm{nm}$ range and by coating them with a conductive layer of carbon.

Nanostructured materials as electrode materials possess several advantages: improved kinetics of lithium ions due to 
their small size, large surface area ensuring sufficient contact between electrode materials and electrolyte and reduced strain during lithiation and delithiation. ${ }^{\mathbf{1 4}}$ Among the many kinds of morphologies, one dimensional nanostructures are particularly interesting, because they additionally offer enhanced transport of electrons along the long axial direction, favoring the current collection during cycling, and thus leading to an improvement of the electrochemical performance. ${ }^{\mathbf{1 5 , 1 6}}$ Moreover, one dimensional nanostructures are promising building blocks for flexible batteries. ${ }^{17}$ Therefore, substantial efforts have been devoted to developing strategies for the synthesis of one dimensional electrode materials with high performance in lithium ion batteries. ${ }^{16}$ On the other hand, one dimensional nanostructures suffer from structure degradation and self-aggregation during cycling. ${ }^{16}$ These issues can be overcome, if the one dimensional nanostructures are coated with a conductive material like carbon. The carbon coating not only improves the conductivity, but also acts as an efficient elastic buffer layer to accommodate the volume expansion and contraction during lithium ion insertion and extraction, and thus significantly improves the electrochemical performance. ${ }^{\mathbf{1 8 , 1 9}}$

It has been reported that amorphous electrode materials can be electrochemically more active than the corresponding crystalline phase, because the high atomic/ionic mobility in amorphous structures favors lithium ion diffusion and also alleviates the strain arising from the volume changes during cycling. ${ }^{20}$ However, the electron conductivity in amorphous structures is often poor, which is detrimental to the collection of electrons. Again, carbon coating provides an efficient approach to resolve this issue.

Herein, we report the synthesis of a highly anisotropic and amorphous silicate nanostructure with a carbon coating and its lithium storage properties. The synthesis of these cobalt silicate nanobelts@carbon composites involves the hydrothermal treatment of cobalt-based organic-inorganic nanobelts as a template with an alkaline solution in a glass tube. Under hydrothermal conditions, the $\mathrm{OH}^{-}$ions react with the glass, forming silicate ions which transform the organic-inorganic nanobelts into amorphous cobalt silicate with preservation of the one dimensional particle morphology. The carbon coating is realized by the deposition of phenol formaldehyde resin on the nanobelts, followed by annealing under $\mathrm{N}_{2}$ atmosphere. As a result of the unique structural and compositional design, the composite electrode exhibits outstanding electrochemical performance when tested as an anode material. It can deliver a reversible high capacity of about $745 \mathrm{~mA} \mathrm{~h} \mathrm{~g}^{-1}$ at a current density of $100 \mathrm{~mA} \mathrm{~g}^{-1}$. At a higher current density of $500 \mathrm{~mA} \mathrm{~g}^{-1}$, the composite exhibits an extraordinary long life of 1000 cycles with a stable capacity retention of about $480 \mathrm{~mA} \mathrm{~h} \mathrm{~g}^{-1}$, which is much higher than the theoretical capacity of the commercialized graphite anode. This is the first time that it is demonstrated that such a high capacity and long term cycling stability can be accomplished for metal silicates $\mathrm{M}_{2} \mathrm{SiO}_{4}(\mathrm{M}=\mathrm{Co}, \mathrm{Fe}, \mathrm{Mn}$, etc. $)$ as anode materials.

\section{Results and discussion}

The anisotropic cobalt silicate nanostructures were synthesized in the presence of cobalt-based organic-inorganic hybrid nanobelts as a template. The hybrid nanobelts were prepared according to our previous work, in which their composition was determined to be $\mathrm{Co}(\mathrm{OH})_{0.8}\left(\mathrm{C}_{6} \mathrm{H}_{5} \mathrm{COO}\right)_{1.2}\left(2 \mathrm{C}_{6} \mathrm{H}_{5} \mathrm{COOH}\right)_{0.04} \cdot 1.86 \mathrm{H}_{2} \mathrm{O}^{21}$ The nanobelts have lengths up to hundreds of micrometers, widths of about 50-200 nm, and thicknesses of about 10-20 nm (Fig. S1†). The hydrothermal treatment of these hybrid nanobelts in a glass tube under alkaline conditions reproducibly results in the formation of amorphous cobalt silicate nanobelts. As shown in the scanning electron microscopy (SEM) images (Fig. 1a and b), the products preserve the one dimensional morphology of the template. The sample looks homogeneous, exclusively consisting of nanobelts. In the transmission electron microscopy (TEM) images, we can clearly distinguish between areas of brighter and darker contrast (Fig. 1c-h). The light contrast stems from the silicate nanobelts, while the dark spots represent $\mathrm{Co}_{3} \mathrm{O}_{4}$ nanoparticles. Some of these dark nanoparticles are embedded in the core (Fig. 1e) or are located on the surface of selected nanobelts (Fig. 1f). However, most of the nanobelts are just of light contrast without any dark nanoparticles (Fig. 1c, d, g and h). The nanobelts can reach lengths of 5-10 $\mu \mathrm{m}$ with widths of 150-250 nm. On the basis of atomic force microscopy (AFM) analysis, the thickness of the nanobelts is determined to be about $20-50 \mathrm{~nm}$ (Fig. S2 $\dagger$ ). Therefore, the nanobelts have a width-to-height ratio of 3 to 12.5. The reflections in the X-ray diffraction (XRD) pattern (Fig. S3†) can be assigned to cubic $\mathrm{Co}_{3} \mathrm{O}_{4}$ (JCPDS 42-1467), indicating that the dark nanoparticles in the TEM images are $\mathrm{Co}_{3} \mathrm{O}_{4}$. Energy-dispersive X-ray spectroscopy (EDX) analysis (Fig. S4a†) reveals that besides cobalt and oxygen, there is a significant amount of elemental Si in the nanobelts. Additionally, the EDX element mapping (Fig. S4b-e †) suggests that Si is homogeneously distributed in the sample. The infrared (IR) spectrum (Fig. S5 $\dagger$ ) of the product shows typical bands at $577 \mathrm{~cm}^{-1}$ and $664 \mathrm{~cm}^{-1}$ belonging to $\mathrm{Co}_{3} \mathrm{O}_{4}$ (ref. 22a) and also a pronounced band at $986 \mathrm{~cm}^{-1}$, typical of the Si-O stretching vibration. ${ }^{22 b}$ Based on all these data, it is reasonable to assume that the nanobelts are either composed of cobalt silicate or silica. To determine the exact composition, we performed TEM-EDX analysis (Fig. 2a) and acquired Energy-Filtered Transmission Electron Microscopy (EFTEM) element maps of an individual nanobelt without $\mathrm{Co}_{3} \mathrm{O}_{4}$ nanoparticles. The EFTEM maps in Fig. $2 \mathrm{~b}-\mathrm{f}$ are recorded using a conventional three-window technique from the Co L-edge, the Si L-edge and the $\mathrm{O}$ K-edge. The results show that the light contrast nanobelts are comprised of all three elements $\mathrm{Co}, \mathrm{Si}$ and $\mathrm{O}$ (Fig. 2a-f). Most importantly, the three elements are homogenously distributed within the nanobelt, proving that their composition is cobalt silicate rather than silica. The XRD pattern (Fig. 3) after annealing in air at $800{ }^{\circ} \mathrm{C}$ can unambiguously be assigned to $\mathrm{Co}_{2} \mathrm{SiO}_{4}$ (JCPDS 01-079-0791) and $\mathrm{Co}_{3} \mathrm{O}_{4}$ (JCPDS 42-1467). The high intensity of the $\mathrm{Co}_{3} \mathrm{O}_{4}$ reflections indicates that no $\mathrm{Co}_{3} \mathrm{O}_{4}$ is consumed during annealing, making a reaction between $\mathrm{SiO}_{2}$ and $\mathrm{Co}_{3} \mathrm{O}_{4}$ improbable. Instead, $\mathrm{Co}_{2} \mathrm{SiO}_{4}$ is the result of the crystallization of the amorphous nanobelts, indirectly confirming their composition as cobalt silicate.

Based on the above characterization results, we propose the following mechanisms for the reaction of $\mathrm{Co}(\mathrm{OH})_{0.8}\left(\mathrm{C}_{6} \mathrm{H}_{5}\right.$ $\mathrm{COO})_{1.2}\left(2 \mathrm{C}_{6} \mathrm{H}_{5} \mathrm{COOH}\right)_{0.04} \cdot 1.86 \mathrm{H}_{2} \mathrm{O}$ into cobalt silicate and $\mathrm{Co}_{3} \mathrm{O}_{4}$. During the hydrothermal treatment in aqueous $\mathrm{NaOH}$, 
the hydroxyl ions react with the Co-based precursor particles as well as with the glass tube inside the Teflon container. The Co-based hybrid transforms into cobalt hydroxide, which subsequently reacts with oxygen to give $\mathrm{Co}_{3} \mathrm{O}_{4}$ (eqn (1) $)^{23}$ and with $\mathrm{SiO}_{3}{ }^{2-}$ (product of the reaction of $\mathrm{OH}^{-}$with $\mathrm{SiO}_{2}$ from the glass tube, eqn (2)) to give $\mathrm{Co}_{2} \mathrm{SiO}_{4}$ (eqn (3)).

$$
\begin{gathered}
6 \mathrm{Co}(\mathrm{OH})_{2}+\mathrm{O}_{2} \rightarrow 2 \mathrm{Co}_{3} \mathrm{O}_{4}+6 \mathrm{H}_{2} \mathrm{O} \\
\mathrm{SiO}_{2}+2 \mathrm{OH}^{-} \rightarrow \mathrm{SiO}_{3}{ }^{2-}+\mathrm{H}_{2} \mathrm{O} \\
2 \mathrm{Co}(\mathrm{OH})_{2}+\mathrm{SiO}_{3}{ }^{2-} \rightarrow \mathrm{Co}_{2} \mathrm{SiO}_{4}+\mathrm{H}_{2} \mathrm{O}+2 \mathrm{OH}^{-}
\end{gathered}
$$

The freshly synthesized cobalt silicate nanobelts can be well dispersed in water, as shown in Fig. S6. $\uparrow$ The high stability is ascribed to the relatively large zeta potential of about $-32.6 \mathrm{mV}$, originating from the $\mathrm{OH}^{-}$groups on the surface of the nanobelts, as verified by IR measurement (Fig. S5†). The good dispersibility of the nanobelts in water allows us to uniformly deposit phenol formaldehyde resin (PFR) on them (Fig. S7 $\dagger$ ) by hydrothermal processing of the cobalt silicate nanobelts with phenol and hexamethylenetetramine (HMT). ${ }^{24}$ Under hydrothermal conditions, HMT decomposes into $\mathrm{NH}_{3}$ and formaldehyde (Fig. S8, $\uparrow$ reaction (1)). Then, the newly formed formaldehyde and phenol polymerize into PFR on the surface of the cobalt silicate nanobelts (Fig. S8, $\dagger$ reaction (2)). The PFR coating can be transformed into amorphous carbon by annealing under protection of $\mathrm{N}_{2}$ at $500{ }^{\circ} \mathrm{C}$. The XRD pattern (Fig. S9 $\dagger$ ) indicates that during the carbonization process the $\mathrm{Co}_{3} \mathrm{O}_{4}$ nanoparticles present in the sample are reduced to $\mathrm{CoO}$ (JCPDS 01-070-2856). The absence of any other reflections suggests that the cobalt silicate is still amorphous. SEM analysis (Fig. 4a-d) shows that the nanobelt morphology was wellpreserved after carbon coating. The coated carbon can be clearly detected by EDX (Fig. S10a†). In addition, the element maps (Fig. S10b-f $\dagger$ ) show that Co, Si, O and $\mathrm{C}$ are homogeneously distributed in the sample, indicating a uniform carbon coating on the nanobelts. According to the TEM images (Fig. 4e-g), some CoO nanoparticles, identified by XRD and shown as dark dots, are distributed around the nanobelts. Due to the similar low contrast of the thin sheet-like carbon and the amorphous cobalt silicate nanobelts, it is difficult to distinguish the carbon shell from the nanobelt cores. Nevertheless, the carbon is uniformly coated on the nanobelts, as confirmed by the EDX element maps (Fig. S10f $\dagger$ ). The presence of carbon can be further confirmed by Raman spectroscopy analysis of the composite. In Fig. S11, $\dagger$ we can observe two pronounced peaks. One is located at $1342 \mathrm{~cm}^{-1}$, which can be identified as the D band of carbon, indicating disordered carbon. ${ }^{25}$ The other one at $1582 \mathrm{~cm}^{-1}$ can be assigned to the $\mathrm{G}$ band of carbon, suggesting the presence of graphitic carbon. ${ }^{25}$ The higher intensity of the $\mathrm{G}$ band in comparison to the $\mathrm{D}$ band implies a high ratio of $\mathrm{sp}^{2}$ graphitic carbon in the carbon coating. A higher content

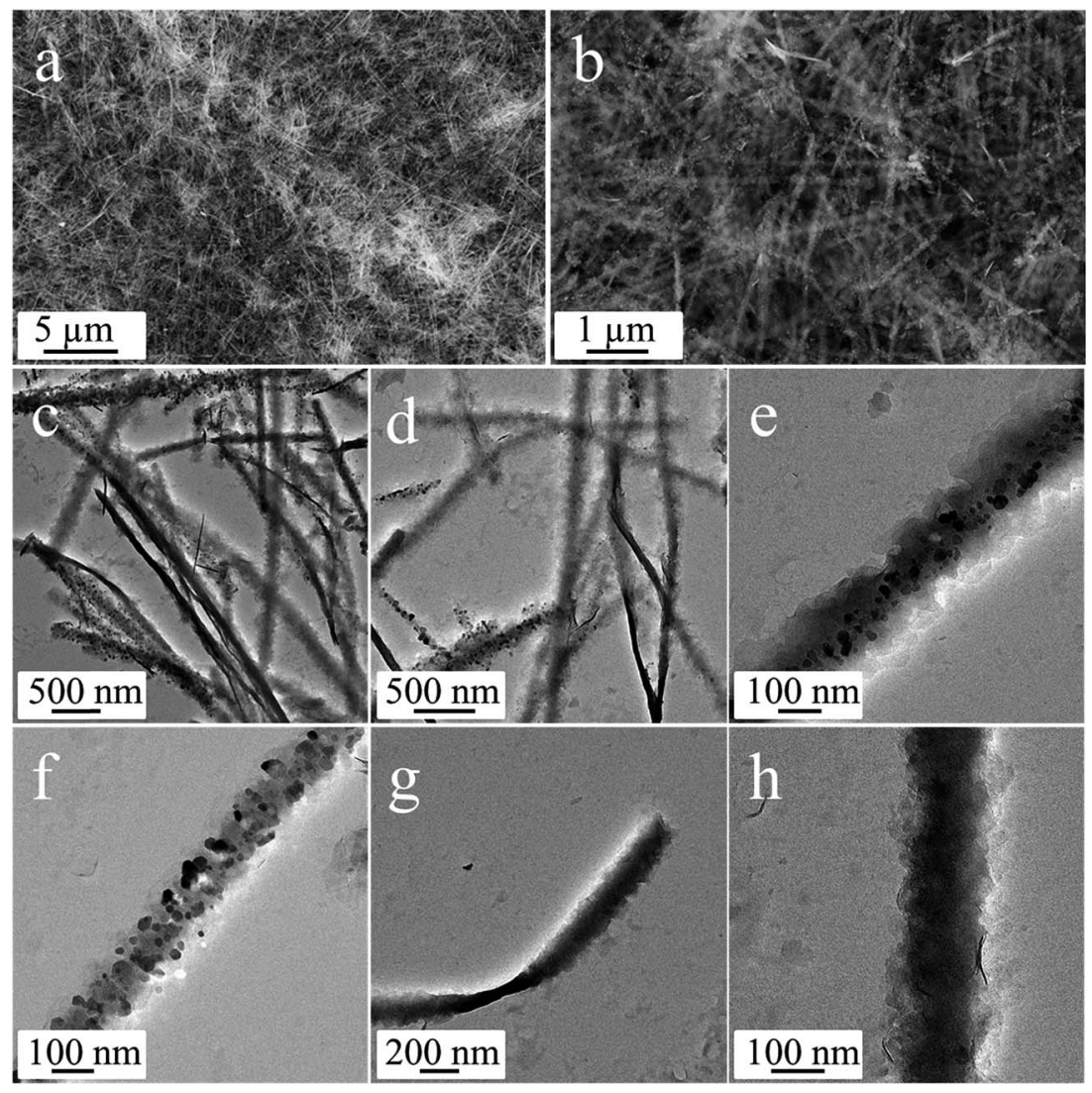

Fig. 1 ( $a$ and b) SEM and (c-h) TEM images of the as-synthesized cobalt silicate nanobelts. 

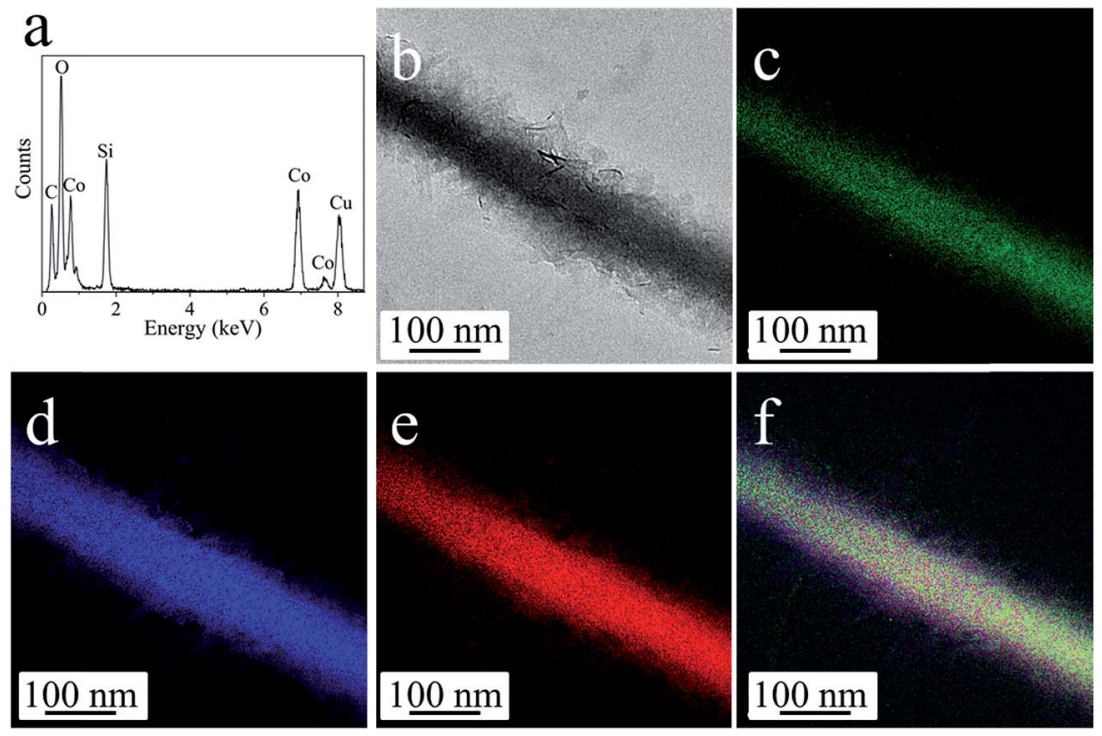

Fig. 2 (a) EDX spectrum taken from a single nanobelt, in which the $C$ and $C u$ signals originate from the TEM grid. (b-f) EFTEM images: (b) zeroloss image, (c) Co L-edge, (d) Si L-edge, (e) O K-edge, (f) overlapping of Co, Si and O maps.

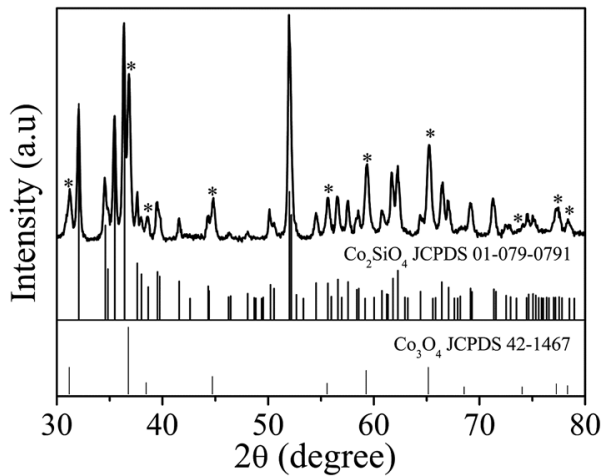

Fig. 3 XRD pattern of the nanobelts $\mathrm{aCO}_{3} \mathrm{O}_{4}$ nanoparticles after annealing in air at $800^{\circ} \mathrm{C}$. The reflections marked with asterisks can be assigned to $\mathrm{CO}_{3} \mathrm{O}_{4}$ (JCPDS 42-1467). All other reflections match with $\mathrm{CO}_{2} \mathrm{SiO}_{4}$ (JCPDS 01-079-0791).

of graphitic carbon gives rise to better electronic conductivity, which is crucial to improve the electrochemical performance of amorphous electrode materials. It is important to mention that the amount of carbon coating can be tuned by using different concentrations of phenol and HMT for the polymerization of PFR on the nanobelts. In a typical synthesis using $6 \mathrm{mM}$ phenol and 3 mM HMT, we obtain cobalt silicate nanobelts@carbon with a weight ratio of $20.9 \mathrm{wt} \%$, as determined by thermogravimetric analysis (TGA) (Fig. S12†). By reducing the concentrations of phenol and HMT by half, the weight ratio of carbon decreases to $9.9 \mathrm{wt} \%$, while a doubling of their concentrations increases the carbon content to $36.7 \mathrm{wt} \%$.

We investigated the potential application of cobalt silicate nanobelts@carbon as an anode material in lithium ion batteries. The $\mathrm{CoO}$ impurities, although in principle electrochemically active, were not removed, because they only represent the minor phase in the cobalt silicate nanobelts@carbon.
Fig. S13† shows the first three cyclic voltammetry (CV) scans of the composite in the voltage range from 0.01 to $3 \mathrm{~V}$. Except for the initial cathodic scan, the current peak positions in the rest of the CV curves are the same as for bulk cobalt silicate, ${ }^{13}$ indicating that our composite undergoes a similar conversion reaction. In this mechanism, the $\mathrm{Co}^{2+}$ is initially reduced to metallic Co nanograins distributed in a $\mathrm{Li}_{4} \mathrm{SiO}_{4}$ matrix and can be restored to cobalt silicate in the subsequent delithiation step. $^{13}$ The mechanism is comparable with the reversible electrochemical reaction of lithium with transition metal oxides, such as $\mathrm{CoO}, \mathrm{Co}_{3} \mathrm{O}_{4}, \mathrm{CuO}$ and $\mathrm{Fe}_{3} \mathrm{O}_{4}{ }^{8,26}$ The peaks in the $\mathrm{CV}$ curves of our composites are, however, less defined than in the case of bulk cobalt silicate, probably due to the amorphous nature of our nanobelts. Clearly, the details of the reaction mechanism need further clarification. Nevertheless, after the irreversible reaction occurring in the initial discharge, all additional CV curves almost overlap, indicating highly reversible lithiation and delithiation reactions for the composite.

Fig. 5a displays representative charge-discharge profiles of cobalt silicate nanobelts@carbon at a current density of 500 $\mathrm{mA} \mathrm{g}^{-1}$ in the voltage window from $0.01 \mathrm{~V}$ to $3.0 \mathrm{~V}$. In the initial discharge, the composite electrode delivers a high capacity of $1159.4 \mathrm{~mA} \mathrm{~h} \mathrm{~g}^{-1}$. Unless otherwise stated, the capacity is calculated based on the total weight of the composite. Considering that the composite contains $20.9 \mathrm{wt} \%$ carbon, the capacity with respect to the cobalt silicate nanobelts is actually as high as $1465.7 \mathrm{~mA} \mathrm{~h} \mathrm{~g}{ }^{-1}$, while the bulk $\mathrm{Co}_{2} \mathrm{SiO}_{4}$ exhibits a first discharge capacity of only $906.0 \mathrm{~mA} \mathrm{~h} \mathrm{~g}{ }^{-1}$ at $80 \mathrm{~mA} \mathrm{~g}^{-1} \cdot{ }^{13}$ In the subsequent charging step, the composite can only deliver a capacity of $620.9 \mathrm{~mA} \mathrm{~h} \mathrm{~g}^{-1}$, corresponding to a coulombic efficiency of $53.3 \%$. The large capacity loss in the first cycle can be ascribed to irreversible electrochemical reactions occurring during the initial discharge, the inevitable formation of the solid electrolyte interphase (SEI) and also electrolyte 


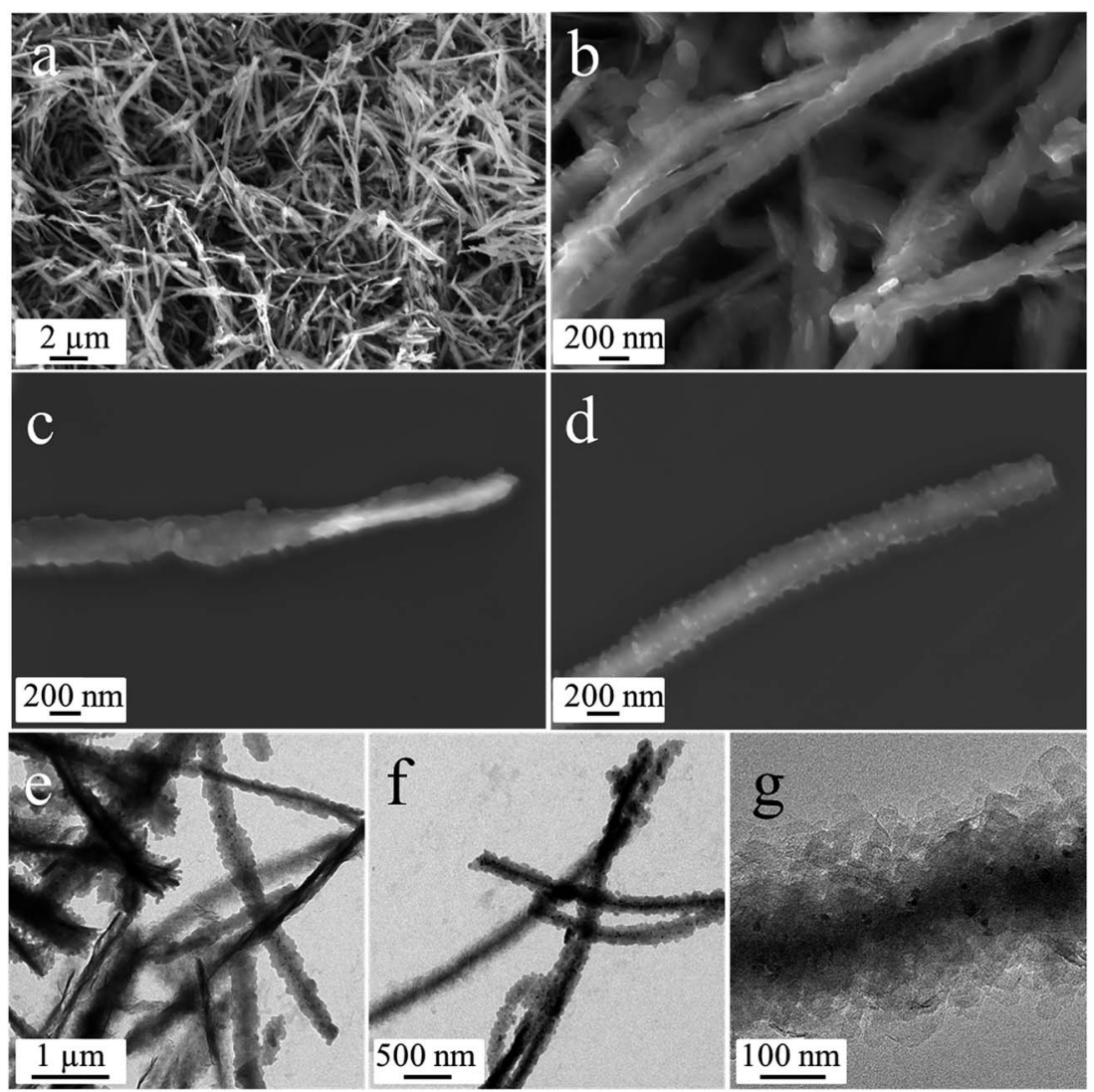

Fig. 4 (a-d) SEM and $(e-g)$ TEM images of cobalt silicate nanobelts@carbon.

decomposition, all of which are commonly observed in most anode materials..$^{10,11,20,26,27}$ After the first discharge-charge cycle, the shapes of the profiles remain basically the same upon further cycling, indicating highly reversible electrochemical reactions, which is in good agreement with the $\mathrm{CV}$ analysis. The coulombic efficiency significantly increases to $87.6 \%$ at the second, $97.3 \%$ at the $10^{\text {th }}$ and $99.1 \%$ at the $20^{\text {th }}$ cycle, then maintains this level upon further cycling.

Fig. 5b (black curve) shows the cycling performance of the composite electrode. Starting from the second cycle, the charge capacity gradually increases from $588.4 \mathrm{~mA} \mathrm{~h} \mathrm{~g}^{-1}$ to $701.0 \mathrm{~mA} \mathrm{~h} \mathrm{~g}{ }^{-1}$ at the $80^{\text {th }}$ cycle, then slowly decreases to $686.4 \mathrm{~mA} \mathrm{~h} \mathrm{~g}^{-1}$ at the $100^{\text {th }}$ cycle. The capacity increase in the first 80 cycles is presumably due to the reversible formation of polymeric layers on the electrode materials, which has already been observed and also confirmed in other transition metal oxide electrode materials with conversion mechanisms. ${ }^{25 a, b}$ As a comparison, we also measured the cycling performance of freshly synthesized amorphous cobalt silicate nanobelts before and after annealing at $500{ }^{\circ} \mathrm{C}$ under $\mathrm{N}_{2}$. The amorphous cobalt silicate before annealing can only deliver a very low initial charge capacity of about $427.9 \mathrm{~mA} \mathrm{~h} \mathrm{~g}^{-1}$, which quickly drops to a low capacity of about $140 \mathrm{~mA} \mathrm{~h} \mathrm{~g}{ }^{-1}$ (Fig. 5b, red). The annealing step does not improve the electrochemical performance (Fig. 5b, green). The bad performance is anticipated to be associated with the poor electronic conductivity of the amorphous cobalt silicate nanobelts. The carbon coated sample shows a more than 5 times higher capacity than the non-coated sample, indicating that carbon coating leads to a dramatic enhancement of the electrochemical performance of the amorphous electrode materials.

The rate performance of the cobalt silicate nanobelts@carbon has also been investigated. Fig. $5 \mathrm{c}$ shows that at $100 \mathrm{~mA} \mathrm{~g}^{-1}$ the capacity of the composite electrode can reach a stable reversible value of about $745 \mathrm{~mA} \mathrm{~h} \mathrm{~g}^{-1}$, while bulk $\mathrm{Co}_{2} \mathrm{SiO}_{4}$ provides a reversible specific capacity of about $600 \mathrm{~mA} \mathrm{~h} \mathrm{~g}^{-1}$ at $80 \mathrm{~mA} \mathrm{~g}^{-1} .^{13}$ Increasing the current density to $200 \mathrm{~mA} \mathrm{~g}^{-1}$, $500 \mathrm{~mA} \mathrm{~g}^{-1}, 1000 \mathrm{~mA} \mathrm{~g}^{-1}$ and $2000 \mathrm{~mA} \mathrm{~g}^{-1}$, the specific capacity is reduced to $688 \mathrm{~mA} \mathrm{~h} \mathrm{~g}^{-1}, 580 \mathrm{~mA} \mathrm{~h} \mathrm{~g}^{-1}, 478 \mathrm{~mA} \mathrm{~h} \mathrm{~g}^{-1}$ and $360 \mathrm{~mA} \mathrm{~h} \mathrm{~g}^{-1}$, respectively. Lowering the current density again to $100 \mathrm{~mA} \mathrm{~g}^{-1}$ results in a capacity of $830 \mathrm{~mA} \mathrm{~h} \mathrm{~g}{ }^{-1}$, which is considerably higher than the $745 \mathrm{~mA} \mathrm{~h} \mathrm{~g}^{-1}$ achieved in the initial 10 cycles at $100 \mathrm{~mA} \mathrm{~g}^{-1}$. In comparison, the nanobelts without carbon coating display very poor rate performance. At a very high current density of $2000 \mathrm{~mA} \mathrm{~g}^{-1}$, almost no capacity can be delivered for the non-coated sample, further confirming the importance of the carbon coating for the enhancement of the electrochemical properties of the amorphous electrode materials.

To further demonstrate the suitability of this unique electrode design as an anode material for lithium ion batteries, we tested the long term stability up to 1000 cycles at $500 \mathrm{~mA} \mathrm{~g}^{-1}$. As displayed in Fig. 5d, for the composite with $20.9 \mathrm{wt} \%$ carbon, in the first 80 cycles the capacity gradually increases to 701.0 

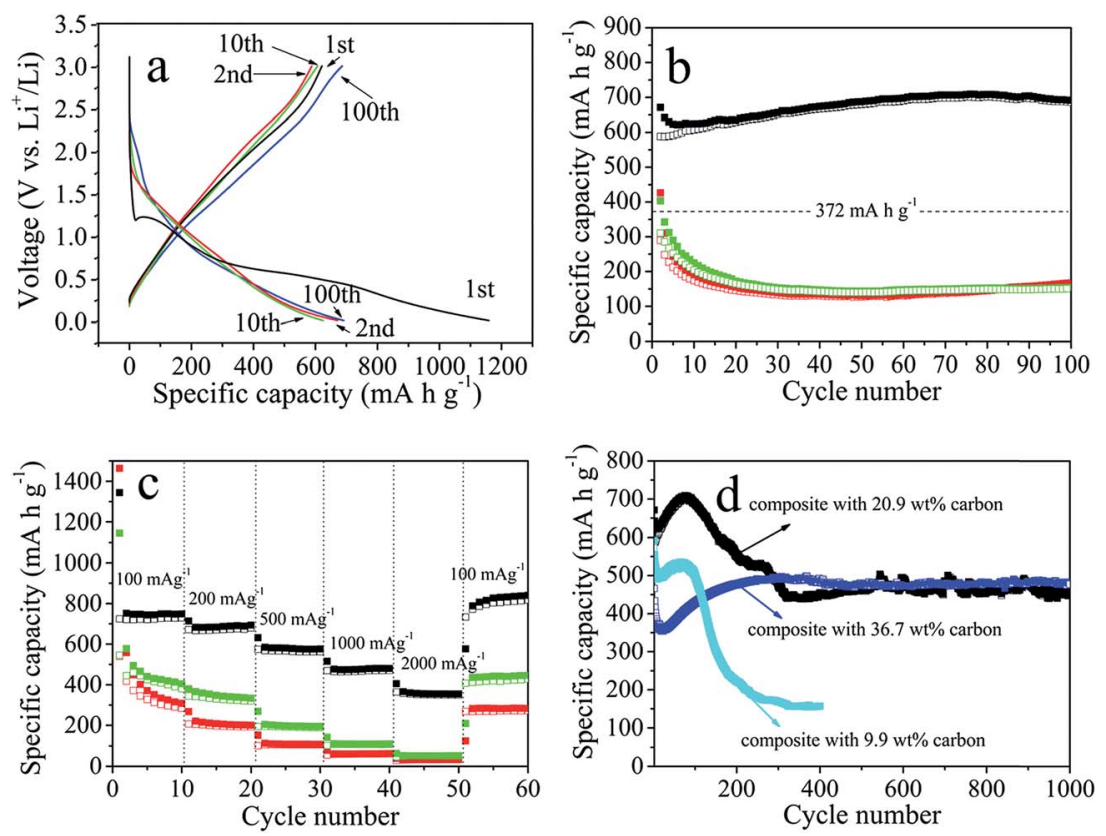

Fig. 5 Electrochemical performance of the cobalt silicate nanobelts@acarbon composites: (a) charge-discharge voltage profiles for the $1^{\text {st }}, 2^{\text {nd }}$, $10^{\text {th }}$ and $100^{\text {th }}$ cycle at $500 \mathrm{~mA} \mathrm{~h} \mathrm{~g}^{-1}$; (b) cycling performance at $500 \mathrm{~mA} \mathrm{~h} \mathrm{~g}^{-1}$ : cobalt silicate nanobelts@carbon composite with 20.9 wt\% carbon (black), as-synthesized cobalt silicate nanobelts (red), and cobalt silicate nanobelts annealed at $500{ }^{\circ} \mathrm{C}$ under $\mathrm{N}_{2}$ (green); (c) rate performance of cobalt silicate nanobelts@carbon composite with 20.9 wt\% carbon (black), as-synthesized cobalt silicate nanobelts (red), and cobalt silicate nanobelts annealed at $500{ }^{\circ} \mathrm{C}$ under $\mathrm{N}_{2}$ (green); (d) long term cycling stability at $500 \mathrm{~mA} \mathrm{~h} \mathrm{~g}{ }^{-1}$ : cobalt silicate nanobelts@carbon composite with 20.9 wt\% carbon (black), composite with 9.9 wt\% carbon (cyan), composite with 36.7 wt\% carbon (blue). Voltage window $0-3.0 \mathrm{~V}$. In $(b-d)$, the solid and empty squares represent the discharge and charge steps, respectively.

$\mathrm{mA} \mathrm{h} \mathrm{g}^{-1}$, followed by a decrease until the $330^{\text {th }}$ cycle. Afterwards, the capacity is very stable up to 1000 cycles with a capacity retention of about $450 \mathrm{~mA} \mathrm{~h} \mathrm{~g}^{-1}$. This value is considerably higher than the theoretical capacity of a graphite anode of about $372 \mathrm{~mA} \mathrm{~h} \mathrm{~g}^{-1}$. It is important to note that the amount of carbon coating has a crucial influence on the cycling performance of the composite electrode materials. As shown in Fig. $5 \mathrm{~d}$, for the composite with $9.9 \mathrm{wt} \%$ carbon, the capacity is much lower than that of the composite with $20.9 \mathrm{wt} \%$. It experiences a slow increase in the initial 80 cycles to $530 \mathrm{~mA} \mathrm{~h} \mathrm{~g}^{-1}$, followed by a drastic decrease to $223 \mathrm{~mA} \mathrm{~h} \mathrm{~g}^{-1}$ after 200 cycles. The low capacity and the poor stability could be due to the insufficient carbon coating, which fails to protect the structural integrity during cycling. Upon increasing the carbon content to $36.7 \mathrm{wt} \%$, the capacity is less than that of both other samples in the initial 110 cycles. However, in contrast to the other two samples with less carbon, the capacity does not show an obvious drop after the initial increase, but continues to rise to $480 \mathrm{~mA} \mathrm{~h} \mathrm{~g}^{-1}$ at the $300^{\text {th }}$ cycle. Then, the value remains at this level until 1000 cycles are reached. Obviously, the large amount of carbon coating compromises the capacity in the initial cycles, but also promotes the cycling stability. The tunable carbon coating allows us to obtain a composite electrode with optimized electrochemical performance. Such an outstanding long term cycling performance has never been achieved for cobalt silicate and silica. ${ }^{\mathbf{1 1 , 1 3}}$ In fact, such a good cyclability has also been seldom observed for other conversion-type transition metal oxide anodes. ${ }^{25-27}$
The attractive electrochemical properties of our cobalt silicate nanobelts@carbon composite can be interpreted from the following perspectives. First of all, based on the aforementioned results, the carbon coating plays a central role in achieving the extraordinary electrochemical performance. The carbon layer can significantly increase the electronic conductivity, which solves the issue of the poor conductivity as a result of the amorphous nature of the cobalt silicate nanobelts. Additionally, it keeps the electrode structure intact and prevents particle aggregation typically caused by the volume expansion and contraction during cycling, greatly improving the cycling stability. We performed TEM analysis of the electrode materials after cycling. For the carbon coated sample, the one dimensional structure is well preserved after long term cycling. No apparent structure damage or collapse was observed (Fig. S14 $\dagger$ ). The nanobelts without carbon coating, on the other hand, suffer severely from structural fracture and particle agglomeration (Fig. S15†), giving evidence for the critical role of the carbon coating for the preservation of the structural integrity of the nanobelts. Moreover, it is known from the literature that the carbon coating is able to limit the thickness of the SEI layer and prevents the cracking of the SEI layer, hence effectively avoiding irreversible capacity during charge and discharge. ${ }^{18,19}$ Secondly, the thin nanobelt structures offer a short lithium diffusion pathway along the direction perpendicular to the nanobelts, while the electron transport along the long axial direction of the composite facilitates the current collection. The composite exhibits a large Brunauer-Emmett-Teller (BET) surface area of 
about $440 \mathrm{~m}^{2} \mathrm{~g}^{-1}$ (Fig. S16 $\dagger$ ), which ensures an optimal contact between the electrode and the electrolyte, and thus supports the lithium ion flux from the electrolyte into the electrode material. Thirdly, the cobalt silicate nanobelts here are amorphous, and the relatively high atomic and ionic mobility in amorphous materials with homogeneous, isotropic texture favors the lithium ion diffusion and mitigates the strain caused by the volume change during cycling. ${ }^{20}$ The synergistic effect of these advantageous features contributes to the final substantial improvement of the electrochemical performance of the composite electrode.

\section{Conclusions}

In summary, we developed a template method for the synthesis of amorphous cobalt silicate nanobelts with high aspect ratios. Their good dispersibility in water enables us to deposit phenol formaldehyde resin on their surface, which can easily be transformed into a carbon layer. The resulting cobalt silicate nanobelts@carbon composites exhibit excellent lithium ion storage properties. Specifically, they can deliver a highly reversible capacity of $745 \mathrm{~mA} \mathrm{~h} \mathrm{~g}^{-1}$ at a current rate of 100 $\mathrm{mA} \mathrm{h} \mathrm{g}^{-1}$. The long term cycling test shows that at a current density of $500 \mathrm{~mA} \mathrm{~g}^{-1}$, the composite can be cycled 1000 times with a high remaining capacity of $480 \mathrm{~mA} \mathrm{~h} \mathrm{~g}^{-1}$. Our study reveals that the carbon coating holds the key to the excellent electrochemical behavior. In addition, the one dimensional and amorphous nature of the composite might also contribute to the superior electrochemical properties. This study marks the first example to demonstrate that by nanostructure engineering and carbon nanocoating a transition metal silicate is able to deliver a high reversible capacity with an extremely long life span, which makes them a new type of potential anode material for lithium ion batteries. Our work may trigger further research efforts into other nanostructured metal silicates with conductive coatings for energy storage applications.

\section{Acknowledgements}

We thank ETH Zurich, China Scholarship Council and the Swiss National Science foundation (Project No. 200020_144437) for financial support. We acknowledge the use of equipment in the Scientific Center for Optical and Electron Microscopy (ScopeM) of ETH Zurich and in the Electron Microscopy Center of EMPA Dübendorf.

\section{References}

1 J. M. Tarascon and M. Armand, Nature, 2001, 414, 359-367. 2 M. Armand and J. M. Tarascon, Nature, 2008, 451, 652-657. 3 B. Dunn, H. Kamath and J. M. Tarascon, Science, 2011, 334, 928-935.

4 N. A. Kaskhedikar and J. Maier, Adv. Mater., 2009, 21, 26642680.

5 L. Ji, Z. Lin, M. Alcoutlabi and X. Zhang, Energy Environ. Sci., 2011, 4, 2682-2699.
6 S. Goriparti, E. Miele, F. de Angelis, E. Di Fabrizio, R. Proietti Zaccaria and C. Capiglia, J. Power Sources, 2014, 257, 421443.

7 N. Nitta and G. Yushin, Part. Part. Syst. Charact., 2014, 31, 317-336.

8 J. Cabana, L. Monconduit, D. Larcher and M. R. Palacín, Adv. Mater., 2010, 22, E170-E192.

9 M. V. Reddy, G. V. Subba Rao and B. V. R. Chowdari, Chem. Rev., 2013, 113, 5364-5457.

10 (a) C. K. Chan, H. Peng, G. Liu, K. McIlwrath, X. F. Zhang, R. A. Huggins and Y. Cui, Nat. Nanotechnol., 2008, 3, 3135; (b) M. H. Park, M. G. Kim, J. Joo, K. Kim, J. Kim, S. Ahn, Y. Cui and J. Cho, Nano Lett., 2009, 9, 3844-3847; (c) A. Magasinski, P. Dixon, B. Hertzberg, A. Kvit, J. Ayala and G. Yushin, Nat. Mater., 2010, 9, 353-358; (d) N. Liu, H. Wu, M. T. McDowell, Y. Yao, C. Wang and Y. Cui, Nano Lett., 2012, 12, 3315-3321; (e) D. Chen, X. Mei, G. Ji, M. Lu, J. Xie, J. Lu and J. Y. Lee, Angew. Chem., Int. Ed., 2012, 51, 2409-2413; (f) H. Wu, G. Chan, J. W. Choi, I. Ryu, Y. Yao, M. T. McDowell, S. W. Lee, A. Jackson, Y. Yang, L. Hu and Y. Cui, Nat. Nanotechnol., 2012, 7, 310-315; (g) H. Wu, G. Yu, L. Pan, N. Liu, M. T. McDowell, Z. Bao and Y. Cui, Nat. Commun., 2013, 4, 1943; (h) N. Liu, Z. Lu, J. Zhao, M. T. McDowell, H. W. Lee, W. Zhao and Y. Cui, Nat. Nanotechnol., 2014, 9, 187-192.

11 (a) M. Miyachi, H. Yamamoto, H. Kawai, T. Ohta and M. Shirakata, J. Electrochem. Soc., 2005, 152, A2089-A2091; (b) B. Guo, J. Shu, Z. Wang, H. Yang, L. Shi, Y. Liu and L. Chen, Electrochem. Commun., 2008, 10, 1876-1878; (c) M. Sasidharan, D. Liu, N. Gunawardhana, M. Yoshio and K. Nakashima, J. Mater. Chem., 2011, 21, 13881-13888; (d) Y. Yao, J. Zhang, L. Xue, T. Huang and A. Yu, J. Power Sources, 2011, 196, 10240-10243; (e) N. Yan, F. Wang, H. Zhong, Y. Li, Y. Wang, L. Hu and Q. Chen, Sci. Rep., 2013, 3, 1568; (f) Z. Favors, W. Wang, H. H. Bay, A. George, M. Ozkan and C. S. Ozkan, Sci. Rep., 2014, 4, 4605; $(g)$ M. Li, Y. Yu, J. Li, B. Chen, X. Wu, Y. Tian and P. Chen, J. Mater. Chem. A, 2015, 3, 1476-1482.

12 M. S. Islam, R. Dominko, C. Masquelier, C. Sirisopanaporn, A. R. Armstrong and P. G. Bruce, J. Mater. Chem., 2011, 21, 9811-9818.

13 F. Mueller, D. Bresser, N. Minderjahn, J. Kalhoff, S. Menne, S. Krueger, M. Winter and S. Passerini, Dalton Trans., 2014, 15013-15021.

14 P. G. Bruce, B. Scrosati and J. M. Tarascon, Angew. Chem., Int. Ed., 2008, 47, 2930-2946.

15 A. I. Hochbaum and P. D. Yang, Chem. Rev., 2010, 110, 527546.

16 L. Mai, X. Tian, X. Xu, L. Chang and L. Xu, Chem. Rev., 2014, 114, 11828-11862.

17 G. Zhou, F. Li and H. M. Cheng, Energy Environ. Sci., 2014, 7, 1307-1338.

18 L. Su, Y. Jing and Z. Zhou, Nanoscale, 2011, 3, 3967-3983.

19 H. Li and H. Zhou, Chem. Commun., 2012, 48, 1201-1217.

20 (a) Z. Wang, Z. Wang, W. Liu, W. Xiao and X. W. Lou, Energy Environ. Sci., 2013, 6, 87-91; (b) W. S. Chang, C. M. Park, J. H. Kim, Y. U. Kim, G. Jeong and H. J. Sohn, Energy 
Environ. Sci., 2012, 5, 6895-6899; (c) L. F. Cui, R. Ruffo, C. K. Chan, H. Peng and Y. Cui, Nano Lett., 2008, 9, 491495; (d) R. Yi, J. Feng, D. Lv, M. L. Gordin, S. Chen, D. Choi and D. Wang, Nano Energy, 2013, 2, 498-504; (e) X. L. Wang, W. Q. Han, H. Chen, J. Bai, T. A. Tyson, X. Q. Yu, X. J. Wang and X. Q. Yang, J. Am. Chem. Soc., 2011, 133, 20692-20695.

21 M. Cao, I. Djerdj, Z. Jaglicic, M. Antonietti and M. Niederberger, Phys. Chem. Chem. Phys., 2009, 11, 61666172.

22 (a) C.-W. Tang, C.-B. Wang and S.-H. Chien, Thermochim. Acta, 2008, 473, 68-73; (b) M. Stoia, M. Stefanescu, T. Dippong, O. Stefanescu and P. Barvinschi, J. Sol-Gel Sci. Technol., 2010, 54, 49-56.

23 Y. Dong, K. He, L. Yin and A. Zhang, Nanotechnology, 2007, 18, 435602.

24 S. R. Guo, J. Y. Gong, P. Jiang, M. Wu, Y. Lu and S. H. Yu, Adv. Funct. Mater., 2008, 18, 872-879.

25 (a) D. Bresser, E. Paillard, P. Niehoff, S. Krueger, F. Mueller, M. Winter and S. Passerini, ChemPhysChem, 2014, 15, 2177-
2185; (b) D. Bresser, E. Paillard, R. Kloepsch, S. Krueger, M. Fiedler, R. Schmitz, D. Baither, M. Winter and S. Passerini, Adv. Energy Mater., 2013, 3, 513-523; (c) C. He, S. Wu, N. Zhao, C. Shi, E. Liu and J. Li, ACS Nano, 2013, 7, 4459-4469.

26 P. Poizot, S. Laruelle, S. Grugeon, L. Dupont and J. M. Tarascon, Nature, 2000, 407, 496-499.

27 (a) G. Zeng, N. Shi, M. Hess, X. Chen, W. Cheng, T. Fan and M. Niederberger, ACS Nano, 2015, 9, 4227-4235; (b) H. Zhang, L. Zhou, O. Noonan, D. J. Martin, A. K. Whittaker and C. Yu, Adv. Funct. Mater., 2014, 24, 4337-4342; (c) A. Ponrouch, P. L. Taberna, P. Simon and M. R. Palacín, Electrochim. Acta, 2012, 61, 13-18; (d) Y. Sun, X. Hu, W. Luo and Y. Huang, J. Mater. Chem., 2012, 22, 13826-13831; (e) Y. Qi, H. Zhang, N. Du and D. Yang, J. Mater. Chem. A, 2013, 1, 2337-2342; (f) L. Wang, H. Gong, C. Wang, D. Wang, K. Tang and Y. Qian, Nanoscale, 2012, 4, 6850-6855. 